\title{
USE OF ENVIRONMENTAL LIFE CYCLE ASSESSMENT TO EVALUATE ALTERNATIVE AGRICULTURAL PRODUCTION SYSTEMS
}

\author{
S.J. COWELL \\ Centre for Environmental Strategy, University of Surrey, \\ Guildford, Surrey GU2 5XH
}

\begin{abstract}
LCA is an environmental management tool for assessing the comprehensive environmental impacts of products, processes and activities. Assessment is undertaken along the life cycle from extraction of raw materials, through processing, manufacturing, transportation, use and on to final disposal. This is illustrated by reference to a study of breadmaking wheat production where the relative environmental impacts of conventional versus less intensive agricultural production systems are compared. Use of life cycle thinking helps to focus attention on "hot spots" for optimising the environmental performance of systems, and broadens the debate to include the wider environmental impacts of alternatives.
\end{abstract}

Keywords: Life Cycle Assessment, environmental management, agriculture.

\section{INTRODUCTION}

Environmental Life Cycle Assessment is an environmental management approach that is increasingly being integrated into company and governmental decisionmaking. At a conceptual level, it is called "life cycle thinking," and approaches such as Product Stewardship and Producer Responsibility are built on this concept. However, the need for a more rigorous application of life cycle thinking to evaluate products and services has led to development of the environmental management tool Life Cycle Assessment (LCA) which is a type of systems analysis. The basic approach in life cycle thinking and LCA is demonstrated in Fig. 1. The conventional approach to environmental assessment is represented by system boundary 1, drawn around a manufacturing process, plant, or factory. However, the approach exemplified by

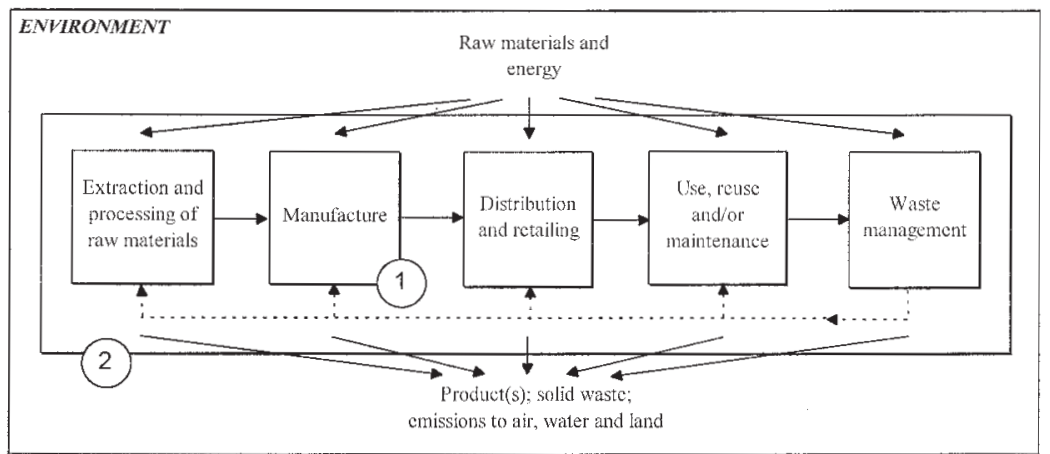

Source: Hodgson et al., 1997.

FIGURE 1: Generic flow diagram for life cycle thinking and LCA.

Proc. 52nd N.Z. Plant Protection Conf. 1999: 40-44 
system 1 is too limited to assess sustainability. The materials and energy used in production must be obtained from primary resources and processed before use, while any products have further environmental impacts in the way they are used and ultimately recycled or disposed. Therefore, LCA extends the system to boundary 2 in Fig. 1. In this way, the "cradle-to-grave" environmental impacts of any products or services under analysis are considered as part of the life cycle.

In LCA methodology, four different phases can be distinguished (Consoli et al. 1993): Goal Definition and Scoping; Inventory Analysis; Impact Assessment; and Improvement Assessment (or "Interpretation"). The first LCA phase, Goal Definition and Scoping, involves defining the purpose of the study, its scope, data quality goals, and functional unit. The functional unit is the unit of analysis defined for the study; it is defined according to the service delivered by the system under analysis. At the Inventory Analysis phase, the environmental burdens (or "interventions" according to ISO 14040 terminology) associated with the life cycle for the functional unit are quantified. These are the material and energy inputs and product, waste, and emission outputs to air, water, and land. During the Impact Assessment phase, the environmental burdens calculated in the analysis are "translated" into environmental impacts. The objective of this phase is to present the environmental impacts of the system under analysis in a form that is useful for the purpose of the study and that can be understood by users of the study results. Types of impact assessment categories considered include depletion of abiotic resources, global warming, acidification, eutrophication and toxicity. The final phase of an LCA is Improvement Assessment or Interpretation where the study results are evaluated and options for reducing the environmental impacts of the functional unit are identified. In practice, LCA involves a series of iterations between these phases as a study's scope is redefined on the basis of insights gained throughout the study.

The advantages of undertaking LCA studies include:

- Cradle-to-grave analysis: any trade-offs between improvements at one stage, and increased impacts at another stage of the life cycle are revealed.

- Multi-criteria assessment: a range of environmental impacts are considered, which helps to avoid single-issue based decision-making.

- Unit of analysis ("functional unit") is service provided: the environmental impacts of alternative systems providing the same service are comparable because they have the same functional unit.

\section{A CASE STUDY}

This section introduces some results from a case study of three breadmaking wheat production systems undertaken by Cowell (1998):

- System A: An intensive production system on a large arable farm without animal production, typical of East Anglia in the UK. It has a high input level of synthetic fertilisers and pesticides. Forty percent of the straw is baled and the remainder incorporated. The grain yield is 8 tonnes/ha with a protein content of $12 \%$.

- System B: A reduced input (integrated) system on a non-livestock farm, typical of wheat grown in Switzerland. Thomas meal (a waste product from steel production) is used as phosphate fertiliser together with other synthetic fertilisers and pesticides. All the straw is incorporated. The grain yield is 6 tonnes/ha with a protein content of $11 \%$.

- System C: A low input system on an organic farm in Switzerland. Farm manure and mechanical or manual weed control are used instead of synthetic fertilisers and pesticides. All the straw is baled. The grain yield is 4 tonnes/ha with a protein content of $12 \%$.

The processes considered in the study are shown in Fig. 2. They include energy and material production; fertiliser and pesticide production; agricultural machinery production, maintenance and storage; on-farm activities; and soil-related processes. Careful modelling was necessary in order to account for all the relevant aspects. For example, at Goal Definition and Scoping the functional unit was defined as "that quantity of wheat grain containing $120 \mathrm{~kg}$ protein" rather than "X kilogrammes wheat 
grain" because the protein content of the grain is critical in breadmaking. Also, other parts of the crop rotation without economic outputs (such as fallow periods and green manure crops) had to be allocated among the crops with economic value in the rotation.

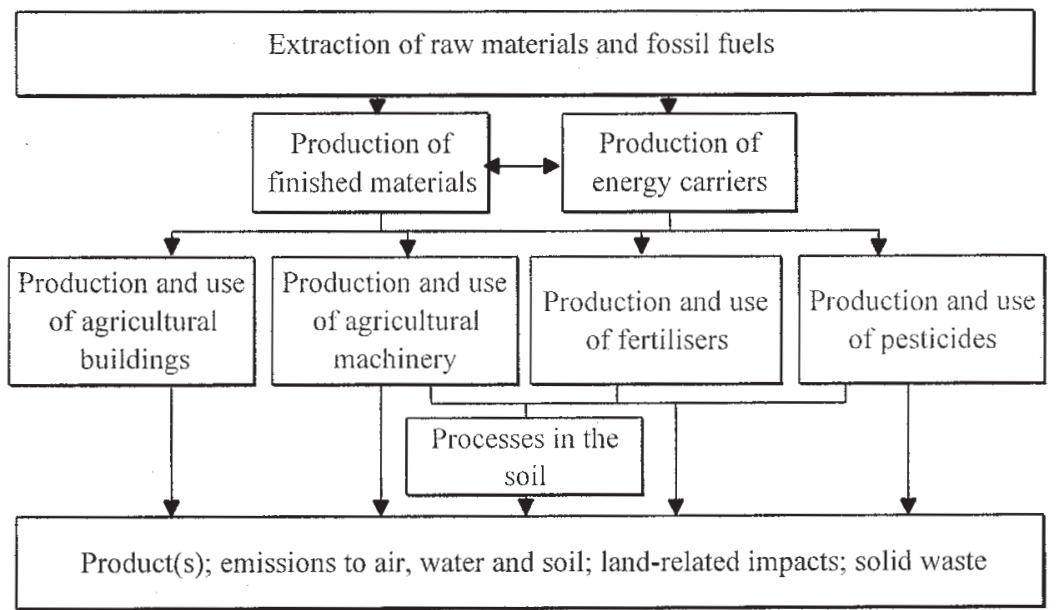

FIGURE 2: Processes considered in case study of breadmaking wheat production.

Some selected results are shown in Figs. 3, 4 and 5, focussing on energy-related results to illustrate the value of the LCA approach. Fig. 3 shows the total energy balances for the three systems. It can be seen that all three systems use fairly similar quantities of fossil-fuel sourced energy in delivery of the functional unit. However, System C requires a much greater land area than the other two systems, and by implication monopolises a much greater amount of incident solar radiation. One conclusion might be that, for a similar input of fossil fuel-sourced energy, Systems A and B use land and incident solar radiation more efficiently than System C.
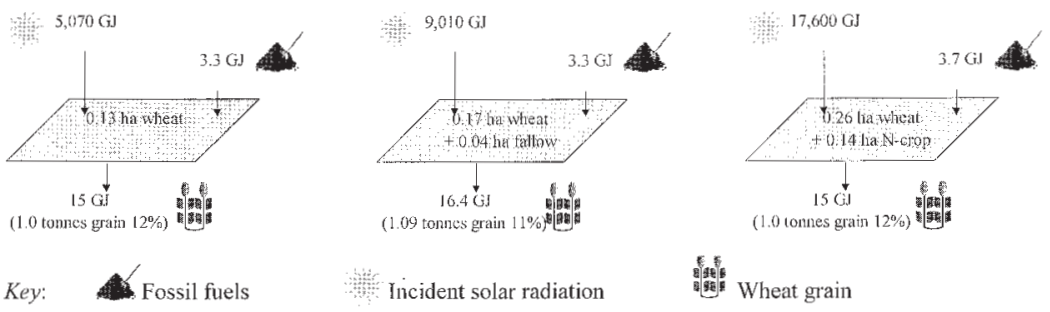

FIGURE 3: Use of energy by systems under analysis.

Fig. 4 shows two sets of results for total fossil fuel-sourced energy use in delivery of the functional unit when alternative fates of the straw are included in the analysis. In Fig. 4a, it is assumed that the baled straw is used as livestock bedding which is eventually reincorporated into agricultural soil. In Fig. 4b, it is assumed that the baled straw is burned for energy recovery - in this case, electricity that displaces fossil-fuel sourced electricity on the National Grid. It can be seen that the assumed fate of the straw has a large influence on the results: in fact, for System $C$ there is a negative 
energy balance when the straw is burned for energy recovery, i.e. more fossil fuelsourced energy is displaced than is required to cultivate the wheat crop. The implication is that the systems under analysis must be carefully modelled to account for the "knock-on" effects of the activities under analysis.

A) Incorporation of straw

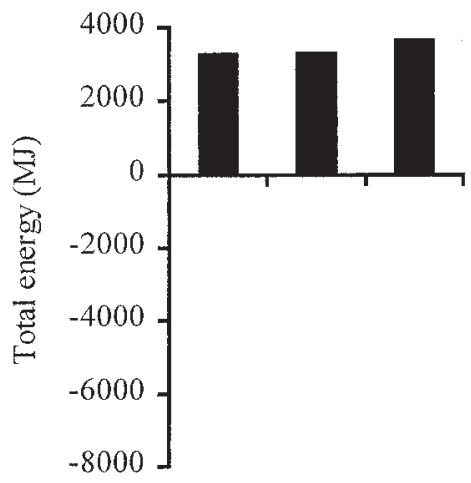

System System System

A $B \quad$ C
B) Generation of Electricity

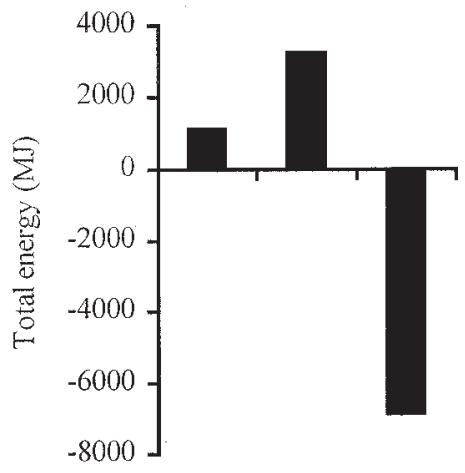

System System System

A $B \quad C$

FIGURE 4: Total fossil fuel-sourced energy use for Systems A, B, C assuming alternative uses of straw.

A) Excluding transportation

for System A

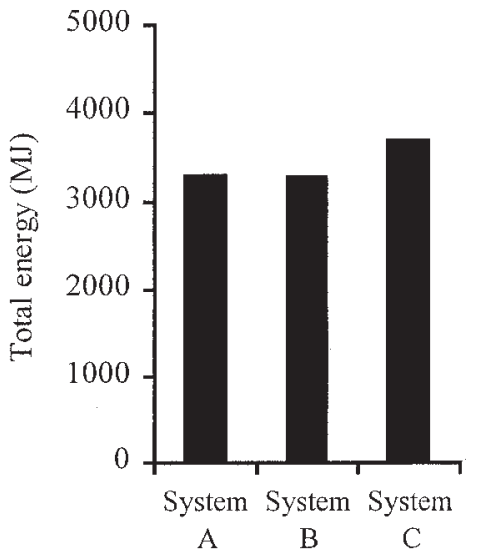

B) Including transportation for System A

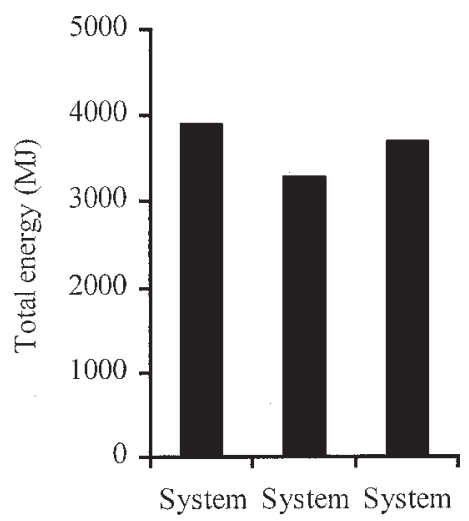

A $\quad B \quad C$

FIGURE 5: Total fossil fuel-sourced energy use for Systems A, B and C excluding and including transportation between location of production and processing/consumption. 
The influence of transportation of the harvested grain is investigated in Fig. 5. Cultivation in Systems B and C takes places in Switzerland whilst System A is located in England. If the grain is subsequently used for breadmaking in Switzerland, the environmental burdens of transporting System A grain from England to Switzerland must be included in the analysis. Fig. 5a shows energy use excluding this transport from the analysis, and Fig. 5b shows total energy use. It can be seen that energy use for transporting grain between the location of agricultural production and location of subsequent processing and consumption is sufficient to alter the ranking of the three systems by total fossil fuel-sourced energy use. This influence on the results will be even more pronounced for other agricultural products where transportation distances are greater and less energy is used in production of the harvested crop.

\section{CONCLUSIONS}

It can be seen that LCA studies such as the one outlined can help to focus attention on those parts of the life cycle contributing the greatest environmental impacts. In evaluation of a system, "hot spots" in its environmental life cycle become obvious, facilitating prioritisation of activities to improve its environmental performance. Also, in comparing alternative systems with environmental impacts at different life cycle stages, the assessment gives a comprehensive overview of the trade-offs between the systems. These benefits of the life cycle approach in environmental management are increasingly recognised as companies incorporate life cycle considerations into their environmental management systems, and country and European Union legislation requires consideration of cradle-to-grave environmental impacts in policymaking.

\section{REFERENCES}

Consoli, F., Allen, D. Boustead, I., Fava, J., Franklin, W., Jensen, A.A., de Oude, N., Parrish, R., Perriman, R. Postlethwaite, D., Quay, B., Seguin J. and Vigon, B., 1993. Guidelines for Life-Cycle Assessment: A 'Code of Practice.' SETAC, Brussels and Pensacola.

Cowell, S.J. 1998. Environmental Life Cycle Assessment of Agricultural Systems: Integration Into Decision-Making. Ph.D. dissertation. University of Surrey, Guildford.

Hodgson, S., Cowell, S.J. and Clift, R. 1997. A Manager's Introduction To Product Design and the Environment. The Environment Council, London. 